\title{
Effect of Micro Porous Shape on Mechanical Properties in Polypropylene Syntactic Foams*
}

\author{
Hiroyuki MAE $^{* *}$, Masaki OMIYA ${ }^{* * *}$ and Kikuo KISHIMOTO ${ }^{* * * *}$ \\ ** Honda R\&D Co., Ltd. \\ 4630 Shimotakanezawa, Haga-machi, Haga-gun, \\ Tochigi 321-1233, Japan \\ Email: Hiroyuki_Mae@n.t.rd.honda.co.jp \\ "** Department of Mechanical Engineering, Keio University \\ ${ }^{*+* * *}$ Department of Mechanical and Sciences Engineering, Tokyo Institute of Technology
}

\begin{abstract}
The objective is to characterize the effect of the microstructure of the micro pores inside the matrix on the mechanical properties of the thermoplastic syntactic polypropylene (PP) foams at the intermediate and high strain rates. Tensile tests are conducted at the nominal strain rates from $3 \times 10^{-1}$ to $10^{2} \mathrm{~s}^{-1}$. In addition, the dart impact tests are conducted at the impact velocities of $0.1,1$ and $10 \mathrm{~m} / \mathrm{s}$. Then, the constitutive law with craze evolution is modified by introducing the relative density, the stress concentration coefficient and the volume fraction of cell edge, and then applied to the dart impact test mode for simulating the macroscopic load displacement history of the dart impact process. Moreover, the microstructural finite element analysis is conducted to characterize the local stress states in the microstructure. In the tensile loading, the elastic modulus is not influenced by the shape of the micro pores in the PP matrix while the yield stress and the strain energy up to failure are relatively influenced by the shape of micro pores. The microstructural finite element analysis shows that the magnitudes of the localized stresses at the edges and the ligaments of the elliptical-shape micro pores are larger than those at the spherical micro pores, leading to the early yielding and the small material ductility. In the case of the dart impact loading, the microstructure of pores has strong effect on the absorbed energy. This is because the elliptical-shape micro pores are very sensitive to the shear deformation, which is revealed by the microstructural finite element analysis. The modified constitutive law with the stress concentration coefficient and the volume fraction of the cell edges successfully predicts the load-displacement curve of the dart impact loading in the spherical micro-porous PP foam. It is concluded that the micro porous shape has strong effect on the material ductility especially in the dart impact test, leading to the possibility to control the material ductility by the shape of the micro pores in the polymeric foams.
\end{abstract}

Key words: Polymer, Strain Rate, Relative Density, Craze, Stress Concentration, Microballoon, Syntactic Foam, Cellular Microstructure, Finite Element, Polypropylene

\section{Introduction}

The lighter but safer structures are needed for economy, environment and functionality especially for various automotive applications, leading to the increasing usages of aluminum alloys and fiber reinforced plastics in load-carrying structures and safety components of automotives. These concepts aim that the weight of automotive is reduced and thus the energy consumption and emissions to the environment are brought down. The

*Received 7 Feb., 2008 (No. 08-0074) [DOI: 10.1299/jmmp.2.616] 
mechanical properties of such structural materials as cast aluminum alloys and aluminum extrusions were characterized in the previous studies. ${ }^{(1)-(4)}$ The same concern can be applied to the interior and exterior automotive parts such as instrument panels, interior door panels and bumper faces, which are made by polymers. Then, many researches were conducted for improving the mechanical properties of polymeric materials. ${ }^{(5)-(14)}$

Lately, syntactic polymer foams are being used to replace the traditional polymer bulk components for weight reduction. Syntactic polymer foams consist of pores and a matrix polymer material. The spherical pores are usually made by mixing microballoons or foaming gases. For more detailed introduction to the syntactic foams, see Shutov ${ }^{(15)}$, Lawrence and Pyrz ${ }^{(16)}$ and Whinnery et al. ${ }^{(17)}$.

In the automotive applications, the thermoplastic polymer syntactic foams are believed to have many advantages because the usual commercial extruders or injection molding machines are applicable for producing them. The studies about mechanical properties of thermoplastic polymer syntactic foams are very few. According to the limited number of literatures describing their mechanical properties, Lawrence and Pyrz ${ }^{(16)}$ determined and compared the viscoplastic properties of polyethylene syntactic foams made from polyethylene and approximately 40 volume percent of polymer microballoons. However, the mechanical properties at the intermediate and high strain rates were not understood comprehensively. The literature about the effect of strain rate on the mechanical properties of thermoplastic polymer syntactic foams is limited to the macroscopic strain rate effect on the compressive mechanical properties. ${ }^{(18-20)}$ It is expected that the local strain rate in the heterogeneous microstructure is not uniform. Therefore, it is necessary to study if the polymer syntactic foams can be evaluated by macroscopic strain rates such as aluminum foams because polymer shows the strong strain rate dependency. Those properties are important to design and use them for automotive application, especially for impact energy absorbers as well as weight reduction. Then the local strain rate effect on the mechanical properties of the thermoplastic syntactic foams at the intermediate and high strain rates were characterized by the same authors. ${ }^{(21)}$

These studies were based on the syntactic polymer foams which had the spherical pores in the matrix. If the spherical pores inside the matrix are not spherical shape but the ellipsoid or slit-like shapes, it is considered that the local stress states can be different from those of the syntactic foams with the spherical-shape polymer microballoons.

In the practical applications, the impact tensile test results are used for the finite element (FE) analysis in designing the neat polymeric automotive components. ${ }^{(22)}$ Thus, it is interesting to investigate whether the micro porous polymeric materials can be simulated by the same numerical technique as that used for neat polymeric materials, which will be the useful information for the future developments of micro porous polymeric components in the automotive applications.

Therefore, it is important to understand the effect of the shape of micro pores inside the matrix on the macroscopic mechanical properties such as the stiffness and the absorbed energy. Then, the objective of this study is to characterize the effect of the micro porous shape inside the matrix on the mechanical properties of the thermoplastic syntactic foams at the intermediate and high strain rates. The syntactic foams in the present research are two types. One consists of elastically deformable microballoons in a polypropylene (PP) matrix, leading to the spherical-shape holes in the PP matrix. The other is made by the super critical fluid (SCF) gas foaming. Both of them are thin sheet made by the injection molding process because the target final application is the interior or exterior automotive components. The microballoons expand during the injection molding because the liquid isobutene is inside the microballoon and it thermally expands during injection process. On the other hand, the SCF gas foaming makes the spherical pores in the middle layer of the thickness while the elliptical-shape holes are made in the outer layer of the thickness direction because of the 
effect of the shear flow between the melting polymer and the molder during injection process.

In the present study, two different porous sizes are prepared in each type of syntactic PP foam, leading to totally four types of syntactic PP foams. In addition, neat PPs are also prepared for references in both injection machines in this study. All syntactic foams are 10 volume percent of micro pores in the PP matrix. Two neat PPs are made by the same injection machines as those used for preparing the syntactic foams because the injection machine for microballoon blended PP is different from that for SCF gas foaming PP. Then, tensile tests are conducted at the nominal strain rates ranged from $3 \times 10^{-1}$ to $10^{2} \mathrm{~s}^{-1}$. Elastic modulus, yield stress, rupture strain and strain energy up to failure are measured and the fracture surfaces are observed with Scanning Electron Microscopy (SEM). In addition, the dart impact tests are conducted at the impact velocities of $0.1,1$ and $10 \mathrm{~m} / \mathrm{s}$ because it is considered that the applied deformation mechanism is similar to the practical case of the polymeric components in the automotive applications. Moreover, the FE analyses are conducted on the dart impact test mode for simulating the effect of micro pores on the macroscopic load displacement history of the dart impact process by introducing the relative density, the stress concentration coefficient, and the volume fraction of cell edge, to Shizawa constitutive model ${ }^{(23)-(26)}$ modified by the same authors in the previous study ${ }^{(22),(27)}$ while the applicability of the FE analysis is studied for the micro porous polymeric materials. In addition, the microstructural FE analysis is also conducted in order to characterize the local stress states in the microstrctures of the syntactic PP foams. Finally, the effects of the micro porous shapes on the tensile mechanical properties and the dart impact properties are discussed.

\section{Experiments}

\subsection{Materials}

The matrix PP material was the elastomer blended PP where ethylene propylene rubber (EPR) was blended at 30 weight percentage. The mechanical properties of tensile and dart impact tests were characterized on the present material in the previous study. ${ }^{(24),(25)}$ The microballoons were Expancel grade 950-80 (Akzo Nobel) for the small diameter and 950-120 (Akzo Nobel) for the large diameter. The material of microballoon shell was made of polymethyl methacrylate (PMMA). The microballoon was mixed with the pellet of matrix polypropylene at dry condition. Then, the mixed pellet was melted and injected into the molder. The injecting temperature was kept at $200{ }^{\circ} \mathrm{C}$ during manufacturing process. The processing temperature and injecting pressure were kept similar for two types of microballoon blend polypropylene and the neat polypropylene. The other syntactic foam made by the SCF foaming was perchased from the supplier (Prime Polymer, Japan). In SCF foam processing, the $\mathrm{CO}_{2}$ cylinder was connected to the cylinder of the melt-mixing extruder. The PP melt was saturated with $\mathrm{CO}_{2}$ at a predetermined foaming temperature and pressure. After the complete solubilization of the gas in the PP melt was reached, the gas-mixed PP melt was injected to the molder. The detail of SCF foaming can be found elsewhere. ${ }^{(28)-(30)}$ The matrix PP blend used for SCF foaming was the same as that for microballoon blends. Both blends were injection molded to the rectangular plate whose geometry was $150 \times 150 \times 3 \mathrm{~mm}^{3}$. All tensile specimens were cut out of the plates such that the tensile direction was the same as the injection direction. The dart impact test specimen was the same as the injected rectangular plate.

The microstructures of both foams were observed with Confocal Laser Microscope (CLM) after cutting the specimen by diamond cutter after cooling enough. Figure 1 shows the upper-half cross sections taken by CLM of four different syntactic foams. As shown clearly, the micro pores were not located in the outer layer of the thickness direction but 
located in the central layer of the thickness direction. In addition, the microballoon blended PP showed the spherical-shape pores while the SCF PP foam showed the elliptical-shape pores. The range of the diameters of the micro pores in the microballoon blended PP is shown in Table 1 while the pore sizes of the SCF PP foam were not measured because they were far from the spherical shape. In this study, the microballoon blended PPs were named as Balloon 80 and 120, respectively, and the SCF gas foaming PPs as Gas 50 and 250, respectively.

\subsection{Test Methods}

ASTM dumbbell shape (parallel portion width $4.8 \mathrm{~mm}$ ) micro tensile test specimens were used for measuring the strain rate dependent stress strain relationship (ASTM D1708). Figure 2 shows the geometry of the test specimen. The thickness of test specimen was $3 \mathrm{~mm}$.

This study used a servo-hydraulic high-speed impact test apparatus (Shimazu EHF U2H-20L: maximum tensile speed $15 \mathrm{~m} / \mathrm{s}$ ) to obtain mechanical characteristics under medium to high speed deformation. Strain rate is the nominal value calculated by the initial clamping distance of the test specimen which is $22.2 \mathrm{~mm}$. The nominal strain rate ranged from 0.3 to $100 \mathrm{~s}^{-1}$. After tensile tests, the fracture surfaces were observed with FE-SEM (HITACHI S-4300SE/N) to identify the fracture mechanism at the nominal strain rates of 0.3 and $100 \mathrm{~s}^{-1}$. With the same test apparatus as the tensile test, the dart impact test was conducted as shown in Fig. 3. The impact velocities were $0.1,1$ and $10 \mathrm{~m} / \mathrm{s}$. The diameter of the dart was $12.7 \mathrm{~mm}$. The test specimen was a square plate of dimensions $150 \times 150 \times 3$ $\mathrm{mm}$ and was clamped by the square plate which had the $76 \mathrm{~mm}$ diameter hole. After dart impact tests, the macroscopic deformation patterns around the dart penetration area were observed with Optical Microscope (OM).

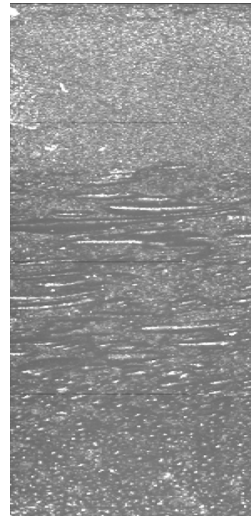

(a) Gas 50

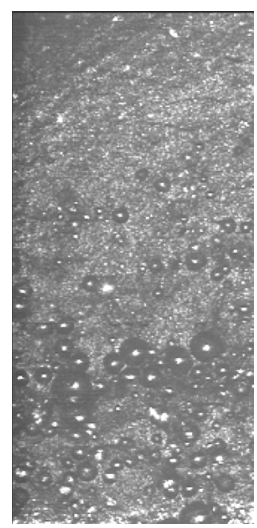

(c) Balloon 80

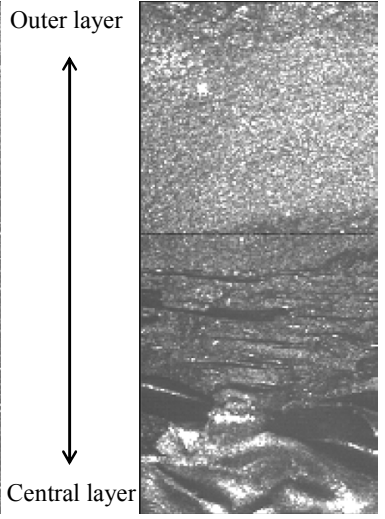

(b) Gas 250

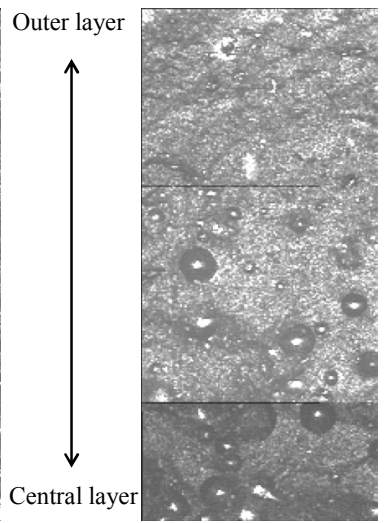

(d) Balloon 120

\section{$500 \mu \mathrm{m}$}

Figure 1 Confocal laser microscope observation for four types of syntactic PP foams 
Table 1 Diameter of microballoons

\begin{tabular}{lccc}
\hline Name & Minimum & Mean & Maximum \\
\hline \hline Balloon 80 & 18.1 & 42.2 & 89.0 \\
Balloon 120 & 24.6 & 55.9 & 99.6 \\
\hline
\end{tabular}

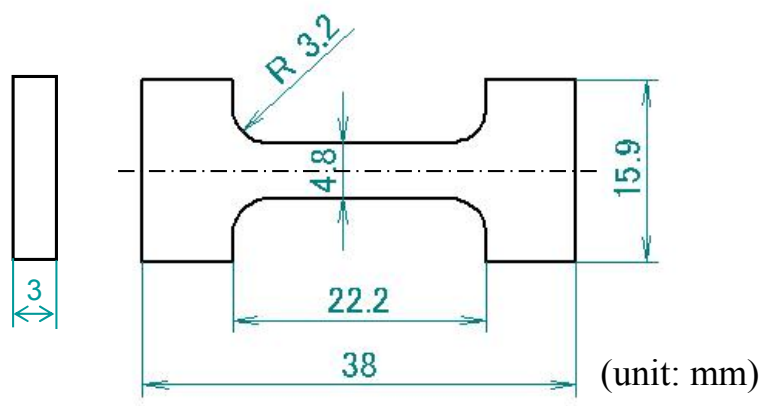

Figure 2 ASTM tensile test specimen

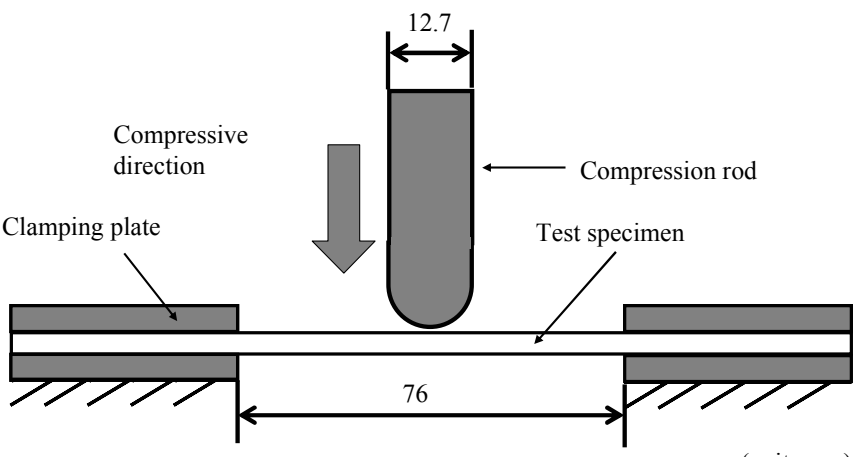

Figure 3 Schematic illustration of dart impact test

\section{Numerical Procedure}

In the previous study, an elastoviscoplastic constitutive law with craze nucleation and growth $^{(23-26)}$ was applied to the dumbbell-shape tensile test, notched tensile test and dart impact test. ${ }^{(22),(27)}$ For simulating the macroscopic mechanical behaviors in the syntactic polymer foams such as the load-displacement histories of dart impact test mode, the relative-density terms are introduced to the constitutive law in the present study. According to the predictions of the theory for conventional foams ${ }^{(31)}$, the tensile modulus of most closed-cell foams can be related to its density

$$
E_{\text {foam }} / E_{\text {neat }} \cong \phi^{2}\left(\rho_{\text {foam }} / \rho_{\text {neat }}\right)^{2}+(1-\phi)\left(\rho_{\text {foam }} / \rho_{\text {neat }}\right),
$$

where $E_{\text {foam }}$ and $E_{\text {neat }}$ are the moduli of the foamed and unfoamed polymers, respectively, and $\rho_{\text {foam }}$ and $\rho_{\text {neat }}$ are the densities of the foamed and unfoamed polymers, respectively. $\phi$ is the fraction of solid in the cell struts. The good approximation for $\phi$ is given in the following equation; ${ }^{(31)}$

$$
\phi=\frac{\left(t_{e} / l\right)^{2}}{0.93^{2}\left(\frac{\rho_{\text {foam }}}{\rho_{\text {neat }}}\right)},
$$

where $t_{\mathrm{e}}$ and $l$ are the thickness and the length of the cell edges, respectively. In the case of the tensile yield stress, the relative yield stress is given in the following equation; ${ }^{(31)-(34)}$

$$
\sigma_{\text {yfoam }} / \sigma_{\text {yneat }} \cong 0.3\left(\rho_{\text {foam }} / \rho_{\text {neat }}\right)^{3 / 2}\left[1+\left(\rho_{\text {foam }} / \rho_{\text {neat }}\right)^{1 / 2}\right\rfloor+(1-\phi)\left(\rho_{\text {foam }} / \rho_{\text {neat }}\right),
$$

where $\sigma_{\text {yfoam }}$ and $\sigma_{\text {yneat }}$ are the yield stresses of the foamed and unfoamed polymers, respectively. Then, the strain hardening equation with strain rate dependent coefficient $m$ is modified in the following equations;

$$
g\left(\bar{\varepsilon}^{p}\right)=\left(\rho_{\text {foam }} / \rho_{\text {neat }}\right) \sigma_{r},\left\{\tanh \left(k_{1} \bar{\varepsilon}^{p}\right)+k_{2}+H_{e}\left(\bar{\varepsilon}^{p}-\varepsilon_{r}\right) k_{3}\left(\exp \bar{\varepsilon}^{p}-\exp \varepsilon_{r}\right)\right\},
$$




$$
\dot{\bar{\varepsilon}}^{p}=\dot{\varepsilon}_{r}\left|\bar{\sigma} / g\left(\bar{\varepsilon}^{p}\right)\right|^{1 / m},
$$

where $\dot{\bar{\varepsilon}} p_{\text {is }}$ the equivalent plastic strain rate, $\dot{\varepsilon}_{r}$ is the reference strain rate, $\bar{\sigma}$ is the equivalent stress, $g\left(\bar{\varepsilon}^{p}\right)$ is the flow stress, $\sigma_{r}$ is the reference stress of neat PP, $\varepsilon_{r}$ is the reference strain at which the second hardening begins. $k_{1}-k_{3}$ are material constants. $H_{e}(\mathrm{x})$ is the following step function.

$$
H_{e}(x)=1 \quad(\text { at } \mathrm{x}>0), \quad 0(\text { at } \mathrm{x}<0) .
$$

In the criterion of the craze generation, it is assumed that the stress states of syntactic foam would be influenced by only one circular pore for simplicity although it is expected that the stress interaction could occur among several pores. Then, the craze generation based on the hydrostatic stress criterion can be modified as Eq. (7);

$$
\sigma_{b} \geq 1 / \alpha\left[A_{1}+\left(B_{1} / 3 \sigma_{m}\right)\right] \quad \sigma_{b}=\sigma_{1}-v \sigma_{2}-v \sigma_{3},
$$

in which $\sigma_{b}$ is the stress needed for fibril orientation, $\sigma_{m}$ is the hydrostatic stress, $\sigma_{1}$ $\sigma_{3}$ are the principal stresses, $\alpha$ is the stress concentration coefficient caused by the micro pores, $A_{I}$ and $B_{I}$ are material constants. In this study, it was assumed that the micro pore was approximated as the hole in the infinite plate for simplicity in order to modify the hydrostatic stress criterion of the craze generation.

The craze evolution equation is proposed in the following equation; ${ }^{(26)}$

$$
\dot{\omega}=A(1-\omega)\left\langle\dot{\varepsilon}_{m}^{p}\right\rangle+0.5 B D_{1}^{\dot{\bar{\varepsilon}}^{p}}\left[1+\tanh \left\{-D_{2}\left(\bar{\varepsilon}^{p}-\varepsilon_{c}\right)\right\}\right] \dot{\bar{\varepsilon}}^{p},
$$

where $A, B, D_{1}$ and $D_{2}$ are material constants. $\dot{\varepsilon}_{m}^{p}$ is the mean normal plastic strain rate modified as

$$
\dot{\varepsilon}_{m}^{p}=\left\{\left(q_{1} \omega\right) \cosh \left(\frac{\left(q_{2} \omega+q_{3}\right) \sigma_{m}}{0.3 \sigma_{\text {yneat }}\left(\rho_{\text {foam }} / \rho_{\text {neat }}\right)^{3 / 2}\left\{1+\left(\rho_{\text {foum }} / \rho_{\text {neat }}\right)^{1 / 2}\right\}+(1-\phi)\left(\rho_{\text {foam }} / \rho_{\text {neat }}\right)}\right)\right\}^{\cdot}
$$

where $q_{1}-q_{3}$ are material constants. The first part of Eq. (8) means craze evolution and the second one means the craze creation and growth. $\varepsilon_{c}$ is the strain at which the craze stops growing. ${ }^{(26)}$ The phenomenological softening law based on craze density is defined as Eq. (10);

$$
f(\omega)=1-\tanh \left\{\left(\omega-w_{2}\right) w_{3}\right\},
$$

where $w_{2}$ is the craze density at which the softening effect starts being activated and $w_{3}$ is the softening parameter. ${ }^{(27)}$ This softening law is multiplied by the flow stress Eq.(4) during each calculation step.

The three-dimensional FE model was constructed for the dart impact test as shown in Fig. 4. The impact velocity was $10 \mathrm{~m} / \mathrm{s}$ in the $z$ direction. Similar to the experiment, the impacting dart was controlled by constant velocities in FE analysis. The axial load and the craze density distribution were obtained by FE analysis. The material parameters for the matrix identified in the previous study ${ }^{(27)}$ are shown in Table 2 with the new parameter of the relative density. The additional material parameters such as the stress concentration coefficient and the fraction of solid in the cell struts were determined based on the morphological pictures. In the case of the microballoon blended PP, $\alpha$ was set as 3 for simplicity because the stress concentration for the infinite plate with a circular hole is 3 . In the case of the SCF gas foaming PP, $\alpha$ was calculated by measuring the mean lengths of the long axis and the short axis of the elliptical pores leading to $\alpha=7$ approximately. The volume fraction of cell edges were set as 0.6 for the microballoon blended PP foams and 0.9 for the SCF gas foaming PP foams by measuring the mean thickness and length of the cell edges based on the morphological pictures for simplicity. In our previous study ${ }^{(21)}$ the relative elastic moduli of the microballoon blended PP at the relative densities ranging from 0.5 to 0.9 were approximated by Eq.(2), leading to $\phi=0.54$ at the nominal strain rate of 50 $\mathrm{s}^{-1}$ and $\phi=0.62$ at the nominal strain rate of $10^{2} \mathrm{~s}^{-1}$. Thus, it is considered that the volume 
fractions of cell edges approximated in this study are reasonable values.

In addition to the dart impact test simulated by the above mentioned constitutive law, the microstructural finite element analysis was conducted. In this analysis, the visco plastic constitutive law in which the experimentally obtained stress strain curves at various strain rates were tabulated was used to estimate the local stress states which were expected to change according to the microstructures. Figure 5 shows the input true stress strain curve of the matrix PP at the strain rates ranging from $10^{-4}$ to $10^{2} \mathrm{~s}^{-1}$ obtained in the previous study. ${ }^{(27)}$ In the microstructural simulation, the rupture was not considered, which meant that the input stress strain curves were extrapolated for the infinite rupture strain. Based on the CLM pictures taken on the cross section before the tensile test as shown in Fig. 1, two dimensional plane strain models were developed by using OOF software. ${ }^{(35)}$ Figure 6 shows the FE mesh models of four types of syntactic PP foams. The mesh size was $6 \mu \mathrm{m}$ for all blends except for the boundaries of pores. The mesh dependency was checked by constructing more fine meshes around the pores. The more fine meshes did not change the stress distribution drastically and the relative relationships of the magnitude of stress components among four types of PP foams. Thus, it was considered that the present mesh models should be reasonable for comparing the stress distributions among all syntactic PP foams in this study. The boundary conditions are shown in Fig. 7. The symmetrical boundary condition was not assumed in the pure shear deformation but it was assumed in the simulation of tensile deformation. The applied deformation rate was $6.4 \times 10^{-2} \mathrm{~m} / \mathrm{s}$ which corresponded to the nominal strain rates of $10^{2} \mathrm{~s}^{-1}$ in the tensile test and the pure shear test. All FE simulations were performed by the commercial explicit finite element code RADIOSS version 4.4. In the case of the dart impact test mode, the constitutive law was executed by the user defined subroutine program.

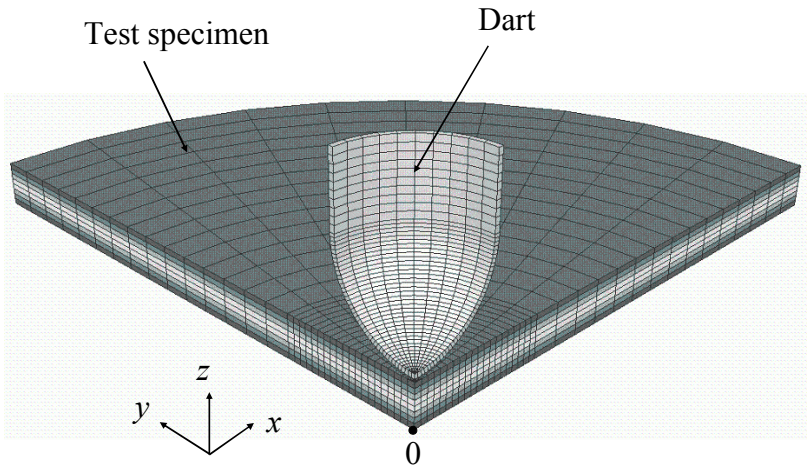

Figure 4 FE model of dart impact test

Table 2 Material parameters

\begin{tabular}{cccc}
\hline$A$ & 0.383 & $\sigma_{r}$ & $10.055(\mathrm{MPa})$ \\
$B$ & 1.226 & $\sigma_{\text {yneat }}$ & $17.432(\mathrm{MPa})$ \\
$A_{1}$ & $1.982(\mathrm{MPa})$ & $k_{1}$ & 44.795 \\
$B_{1}$ & $417.665(\mathrm{MPa} \cdot \mathrm{MPa})$ & $k_{2}$ & 0.863 \\
$D_{1}$ & 0.999 & $k_{3}$ & 1.243 \\
$D_{2}$ & 100.541 & $q_{1}$ & 0.0001177 \\
$\varepsilon_{c}$ & 1.087 & $q_{2}$ & 12.44 \\
$m$ & 0.069 & $q_{3}$ & 2.908 \\
$\dot{\varepsilon} r$ & $1\left(\mathrm{~s}^{-1}\right)$ & $w_{2}$ & 0.22425 \\
$\varepsilon_{r}$ & 0.0001 & $w_{3}$ & 4.0968 \\
$\rho_{\text {foam }} / \rho_{\text {neat }}$ & 0.90 & $E_{\text {neat }}$ & $800(\mathrm{MPa})$ \\
\hline \multicolumn{5}{r}{}
\end{tabular}




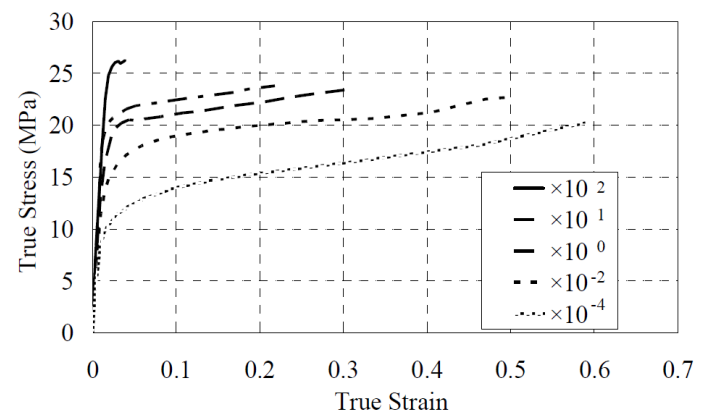

Figure 5 Tensile stress strain curves of neat PP

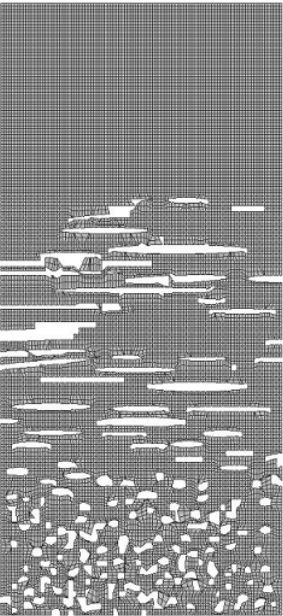

(a) Gas 50

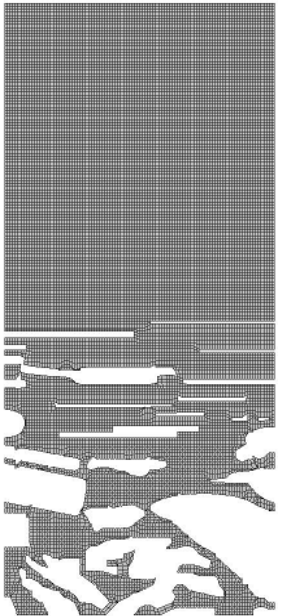

(b) Gas 250

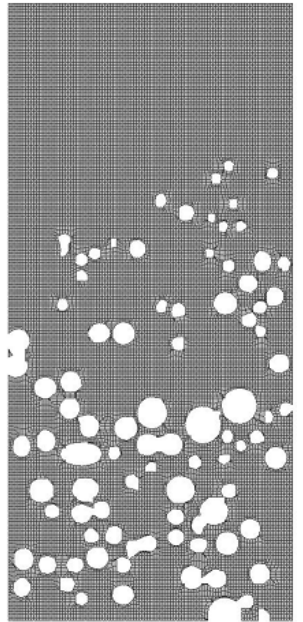

(c) Balloon 80

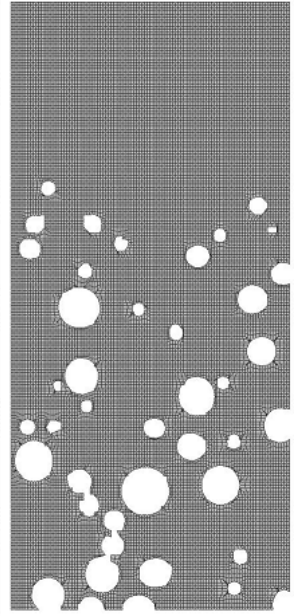

(d) Balloon 120

Figure 6 Microstructural FE models

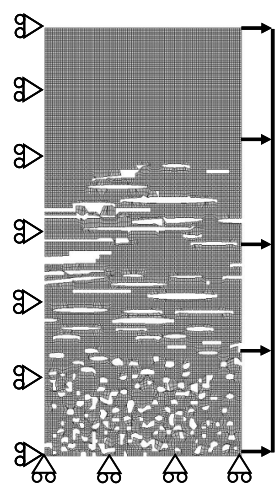

(i) Tensile deformation

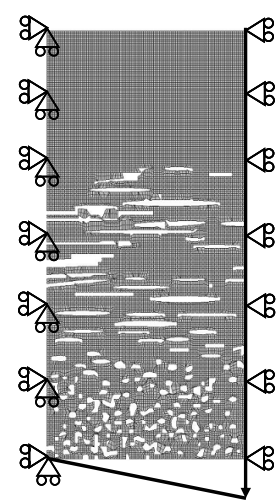

(ii) Shear deformation

Figure 7 Boundary conditions for microstructural FE analysis

\section{Results and Discussions}

\subsection{Experimental Results: Tensile Test}

Figure 8 shows the typical nominal stress strain curves at the nominal strain rate of 10 $\mathrm{s}^{-1}$. The flow stress and rupture strain decreased drastically once the micro pores were embedded inside the materials, regardless of the foaming types. Figure 9 shows the relationship between the apparent elastic modulus and the nominal tensile strain rate of various PP foams. Tensile tests under each condition were conducted three times. The mean values calculated by three measurement data are plotted in Fig. 9. In this study, the microballoon blended PP has three phases which are pores, microballoon's shell and matrix (polypropylene). Thus, it is necessary to investigate the effect of the stiffness of the 
microballoon's shell on the macroscopic stiffness. When it is assumed that all blended microballoon is completely spherical shape, it is estimated that the volume percentage of the microballoon shell is only about $0.08 \%$ at the $10 \mathrm{vol} \%$ of micro pores in the matrix. Note that the elastic modulus of microballoon shell is approximated as $2 \mathrm{GPa}$. Based on the mixing rule, the effect of the elastic modulus of microballoon shell on the macroscopic elastic modulus in the present syntactic foam is negligible. Thus, it can be assumed that the microballoon blended polypropylene consists of the pores and the matrix for simple calculation in this study. As shown clearly in Fig. 9, the apparent elastic modulus increased as the nominal strain rate went up. Based on the results of two types of neat PP, it is considered that the ductile-brittle transition would occur at the nominal strain rates between 10 and $50 \mathrm{~s}^{-1}$. This ductile-brittle transition did not change even though the micro pores were added into the PP matrix as shown in Fig. 9. The difference of the relationship of the apparent elastic modulus and the nominal strain rate was small between the microballoon blended PP (Balloon 80 and 120) and the SCF gas foaming PP (Gas 50 and 250). This is because the volume percentage of pores in the PP matrix is the same among all blends.

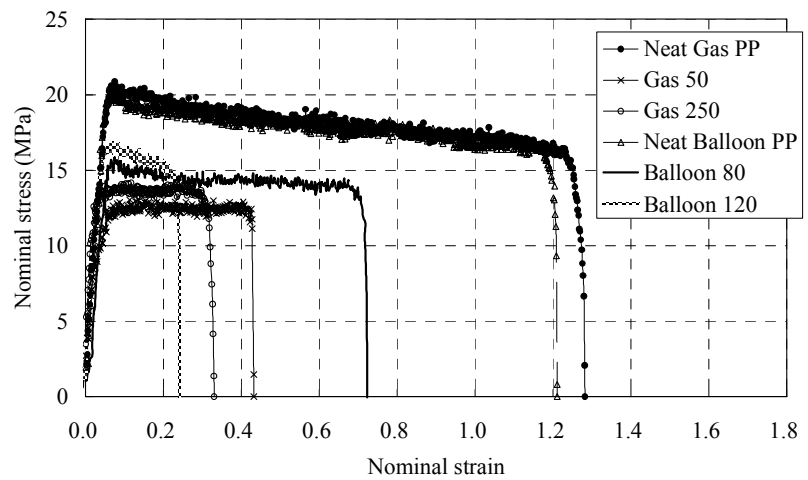

Figure 8 Typical stress strain curves at strain rate of $10 \mathrm{~s}^{-1}$

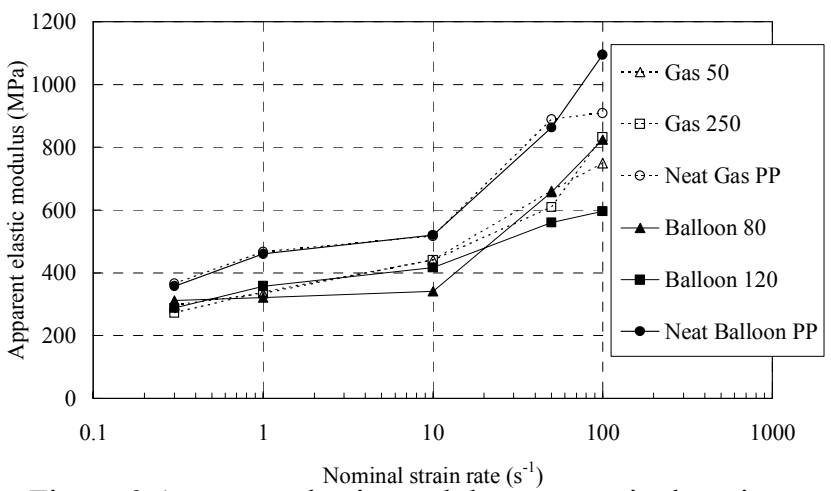

Figure 9 Apparent elastic modulus vs. nominal strain rate

Figure 10 shows the yield stress plotted against the nominal strain rate. The yielding of polymeric materials is very complex. The local damages such as polymer chain scission, micro crazing and so on could occur even in apparent elastic region on the stress-strain curve. Therefore, from a macroscopic point of view, the yield stress was defined as the maximum nominal stress in the stress-strain curve. In the same manner as Fig. 9, the yield stress increased slightly as the nominal strain rate increased. However, the ductile-brittle transition was not observed in the case of yield stress at the nominal strain rates ranging from 0.3 to $10^{2} \mathrm{~s}^{-1}$. The interesting result here is that the decrease of the yield stress by adding the micro pores in the PP matrix was different between the microballoon blended PP and the SCF gas foaming PP. The decrease of the yield stress in the SCF gas foaming PP was larger than that in the microballoon blended PP. It is considered that the microstructural difference should make such differences. On the other hand, the yield stress was similar in the same group such as the microballoon blended PP (Balloon 80 vs. 120) and the SCF gas 
foaming PP (Gas 50 vs. 250). The more detailed study will be discussed in the section of numerical simulation results.

Figures 11 and 12 show the nominal rupture strain and the strain energy up to failure plotted against the nominal strain rate. The trend was similar between Figs. 11 and 12. The rupture strain decreased as the nominal strain rate increased. The decreases of the rupture strain by adding the micro pores in the matrix material in the microballoon blended PP were smaller than those in the SCF gas foaming PP. In addition, the difference of the rupture strain between the microballoon blended PP and the SCF gas foaming PP got smaller as the nominal strain rate increased. It is considered that the fracture mechanisms would shift from ductile mode to brittle mode, leading to the similar rupture strain among all blends. This will be validated in the fractographic analysis. It is noticeable that the rupture strain of Balloon 120 was smaller than that of Balloon 80. The Balloon 120 showed the similar material ductility to the Gas 50 and 250. It is expected that the microstructural difference would play an important role in such a material ductility. This will be discussed in the section of numerical analyses.

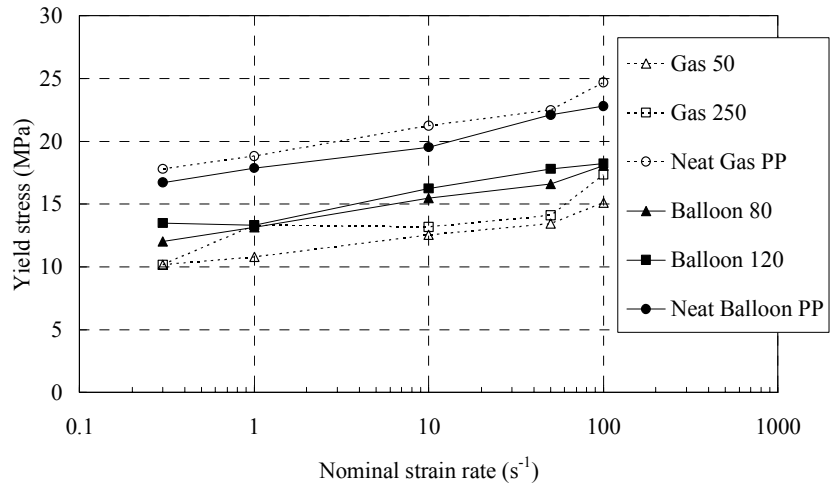

Figure 10 Yield stress vs. nominal strain rate

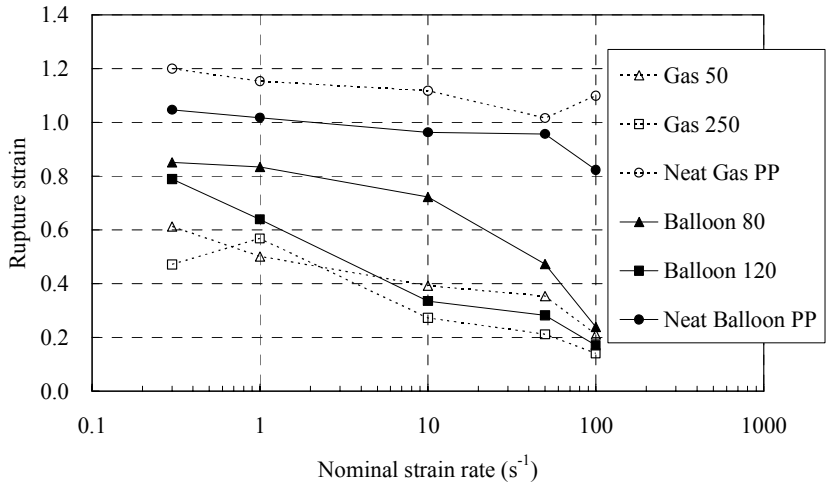

Figure 11 Rupture strain vs. nominal strain rate

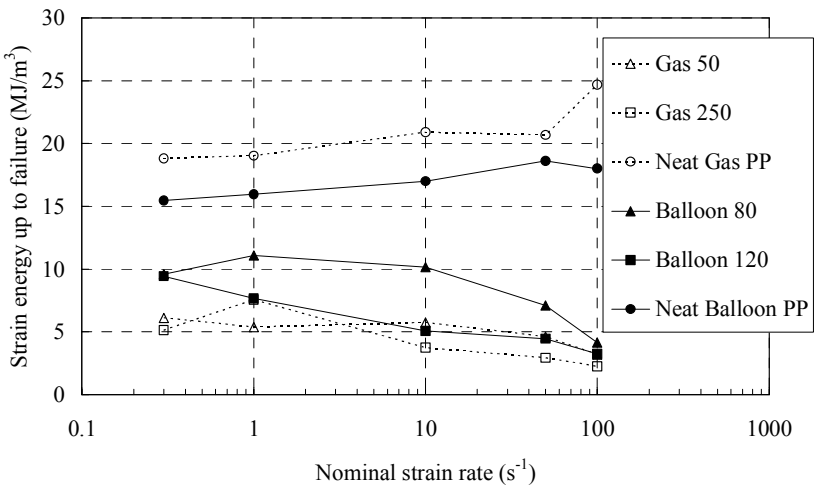

Figure 12 Strain energy up to failure vs. nominal strain rate 


\subsection{Experimental Results: Dart Impact Test}

Figure 13 shows the typical load displacement histories of the dart impact test at the impact velocity of $10 \mathrm{~m} / \mathrm{s}$. As shown clearly, the load-displacement curves were similar among all specimens. The fracture displacement of the SCF gas foaming PP was smaller than that of the microballoon blended PP.

Figure 14 shows the maximum load plotted against the impact velocity in all samples. The maximum load increased as the impact velocity increased. The maximum load was similar between two neat PPs. The differences of the maximum load were quite small between the same types of foams (the microballoon blended PP and the SCF gas foaming $\mathrm{PP})$. This trend is similar to that of the yield stress obtained in the tensile tests.

Figure 15 shows the relationship between the absorbed energy up to failure and the impact velocity. The absorbed energy of the neat PPs increased as the impact velocity increased. On the contrary, the absorbed energy was kept constant in all PP foams while the maximum load increased as the impact velocity went up. In the same manner as Fig. 14, the difference of the absorbed energy was quite small within the PP foams manufactured by the same process. It is noted that the absorbed energy of the SCF gas foaming PP decreased drastically by adding the micro pores in the PP matrix, compared to the case of the microballoon blended PP. The experimental result of the absorbed energy was different from the results obtained in the tensile tests. In the tensile tests, the strain energy up to failure of Balloon 120 was similar to the strain energy of Gas 50 and 250. It is considered that the deformation mechanism of dart impact test would be different from that of tensile test, leading to the different trend of the absorbed energy. The detailed analysis will be discussed in the results of the microstructural FE simulation.

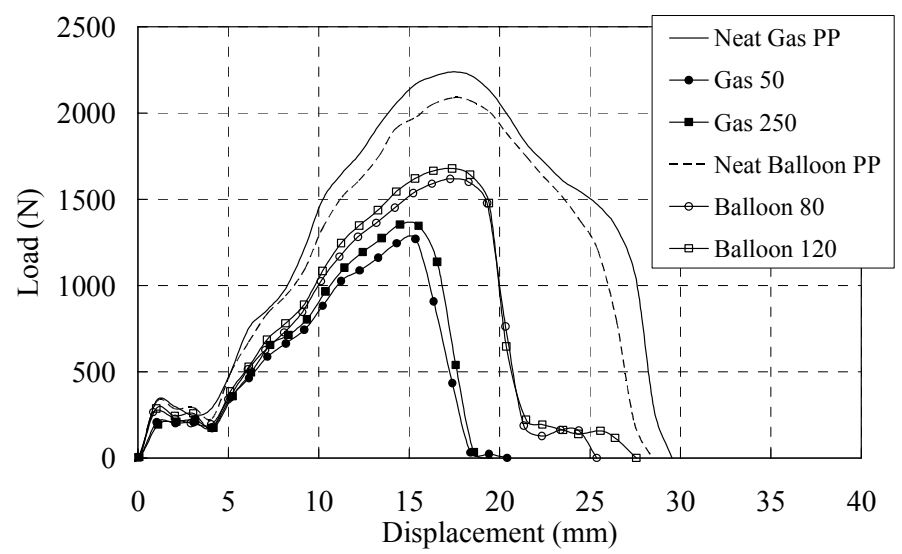

Figure 13 Typical load displacement histories of dart impact test at the impact velocity of $10 \mathrm{~m} / \mathrm{s}$.

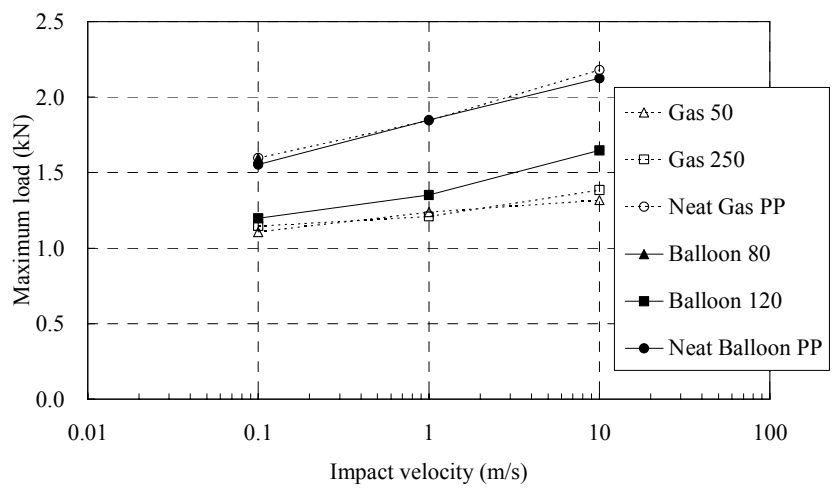

Figure 14 Maximum load vs. impact velocities 


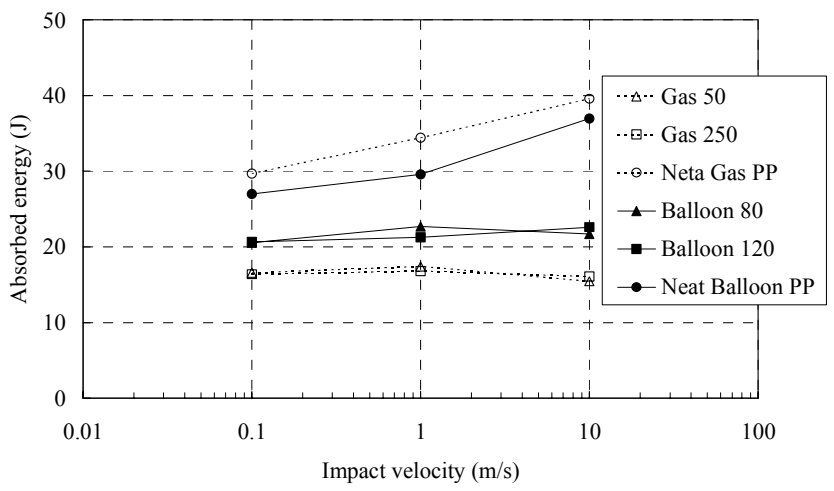

Figure 15 Absorbed energy vs. impact velocities

\subsection{Fractographic Analyses}

To better understand the fracture mechanism of the present PP foams under the low and high strain rates, the fracture surface of each tensile specimen was examined with SEM. Some of the SEM pictures are selectively presented in this paper. In addition, the fractured specimen after the dart impact tests was observed by OM.

Figures 16 show the fracture surfaces of the tensile specimen at the nominal strain rate of 0.3 and $10^{2} \mathrm{~s}^{-1}$. These SEM pictures were low magnified pictures so that the upper half of the thickness direction could be captured in one picture. As shown clearly, the PP matrix between micro pores was highly elongated in both microballoon blended PP and the SCF gas foaming PP, leading to the ductile failure mechanism at the nominal strain rate of $0.3 \mathrm{~s}^{-1}$. On the contrary, the smooth fracture surfaces were obtained at the nominal strain rate of $10^{2}$ $\mathrm{s}^{-1}$ in all the syntactic foams. It is considered that the micro pores would work as the crack initiation site at the high strain rate in all the PP foams. At the low strain rate, the molecules can begin to untangle and relax, leading to the ductile fracture mechanism. However, the high strain rate loading does not give enough time for molecules to untangle and relax, leading to the brittle fracture. This ductile brittle transition can be found in the apparent elastic modulus as shown in Fig. 9. Based on the relationship between the apparent elastic modulus and the strain rate, it is expected that the ductile brittle transition nominal strain rate should range between 10 and $10^{2} \mathrm{~s}^{-1}$ in the present neat PP.

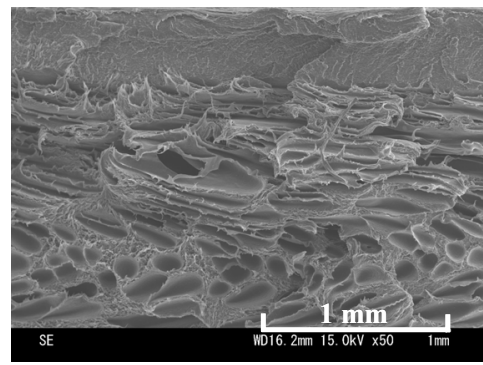

(i) Gas 50

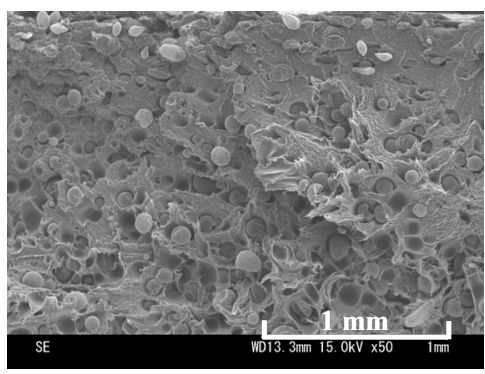

(iii) Balloon 80

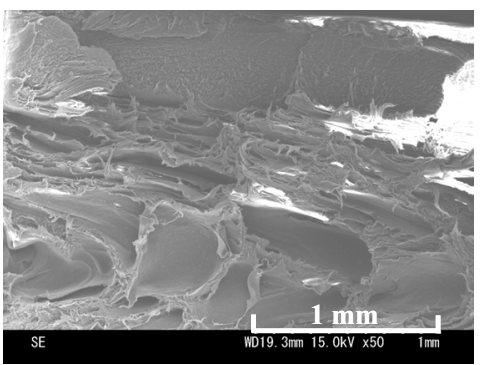

(ii) Gas 250

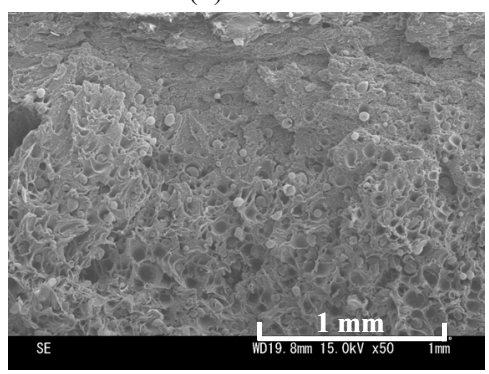

(iv) Balloon 120

(a) At nominal strain rate of $0.3 \mathrm{~s}^{-1}$ 


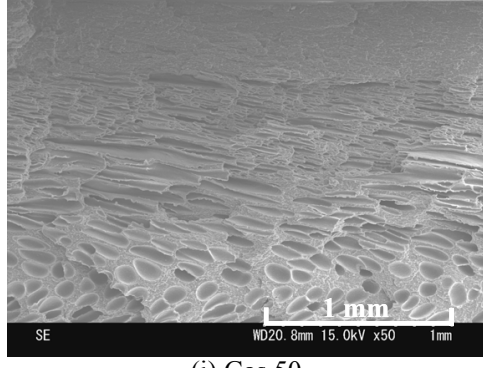

(i) Gas 50

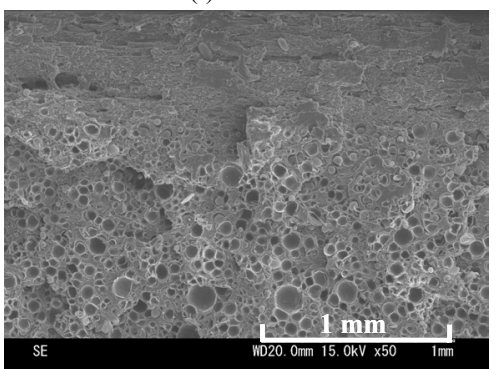

(iii) Balloon 80

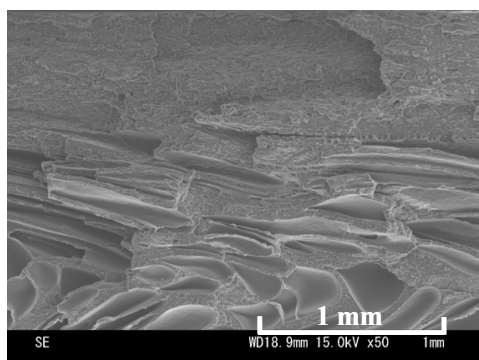

(ii) Gas 250

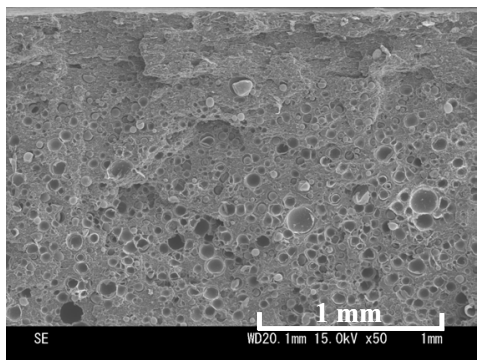

(iv) Balloon 120

(b) At nominal strain rate of $10^{2} \mathrm{~s}^{-1}$

Figure 16 Fracture surfaces of tensile test specimens

Figures 17 and 18 show the OM pictures of the upper and lower surfaces of the fractured specimen of the dart impact tests at the impact velocities of 0.1 and $10 \mathrm{~m} / \mathrm{s}$, respectively. In neat PPs, the ductile fracture was the dominant mechanism at the impact velocities of 0.1 and $10 \mathrm{~m} / \mathrm{s}$. The crazes, which were typical ductile fracture mechanisms of PP, were observed. On the contrary, all the PP foams showed the ductile fracture mode at the impact velocity of $0.1 \mathrm{~m} / \mathrm{s}$ only. At the impact velocity of $10 \mathrm{~m} / \mathrm{s}$, the crazes were partially observed around the dome-shape area but they were not observed along the dart-penetration area. It is considered that the craze would be localized without the large plastic deformation leading to the brittle fracture in both syntactic PP foams (Gas and Balloon) while the large plastic deformation occurred in both neat PPs along the boundary of the dart penetration at the impact velocity of $10 \mathrm{~m} / \mathrm{s}$.

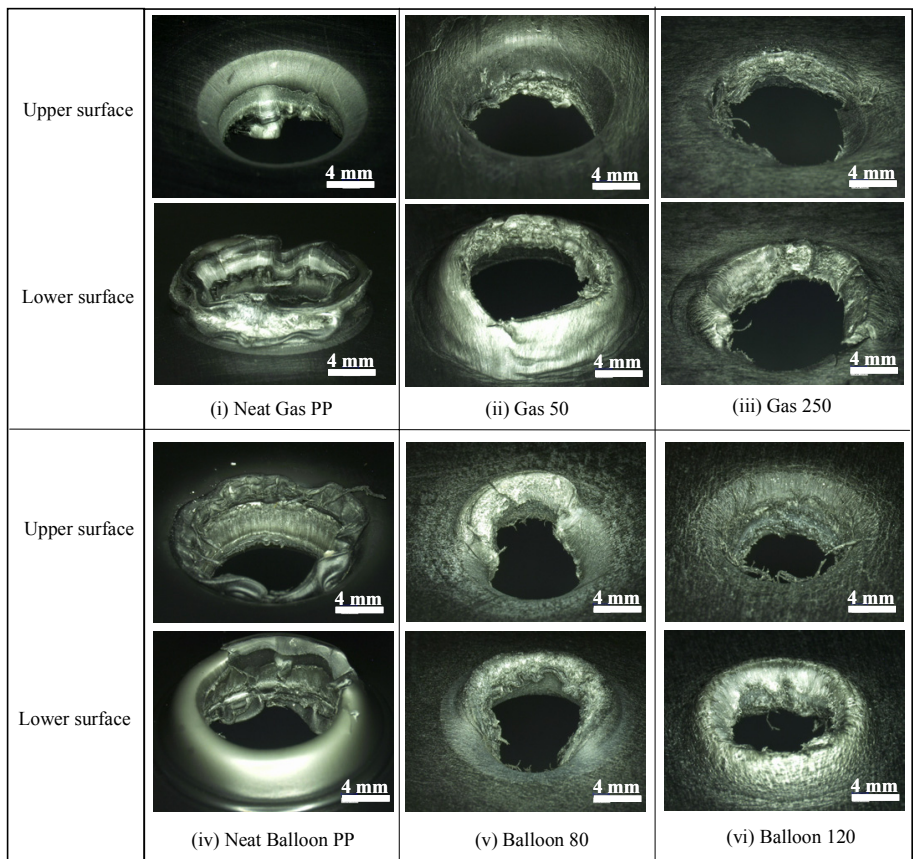

Figure $17 \mathrm{OM}$ pictures of fractured dart impact specimen at the impact velocity of $0.1 \mathrm{~m} / \mathrm{s}$. 


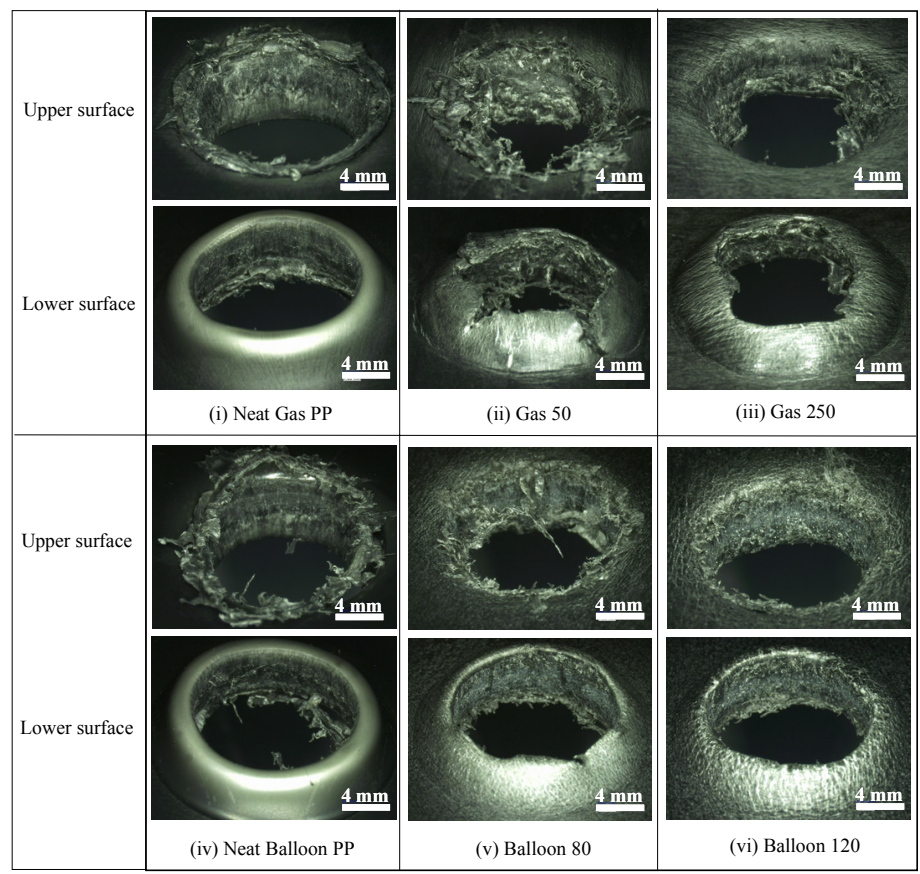

Figure $18 \mathrm{OM}$ pictures of fractured dart impact specimen at the impact velocity of $10 \mathrm{~m} / \mathrm{s}$.

\subsection{Numerical Results: Dart Impact Simulation}

Figure 19 shows the snapshots of the deformation process of neat PP with the craze density distribution during the dart impact process at the impact velocity of $10 \mathrm{~m} / \mathrm{s}$. As the dart displacement increased, the craze density increased around the dart penetrating area. In addition, the deformation was localized at the dart contact area when the dart displacement was $15 \mathrm{~mm}$. Figures 20 and 21 show the equivalent plastic strain rate and the stress states of the upper surface of the dart specimen at the location of $x=y=1.6 \mathrm{~mm}$ plotted against the displacement of the dart. As shown clearly, the mean equivalent plastic strain rate was approximately $10^{2} \mathrm{~s}^{-1}$ during the dart impact process at the impact velocity of $10 \mathrm{~m} / \mathrm{s}$. Thus, for simplicity, the applied nominal strain rate was set as $10^{2} \mathrm{~s}^{-1}$ for the microstructural FE analysis. During the dart impact process, the compressive in-plane stress was applied and then the compressive and shear out-plane stresses were applied after contacting to the dart surface at the location of $x=y=1.6 \mathrm{~mm}$. As the dart displacement increased, the in-plane tensile stress and out-plane shear stress were the dominant stress components. Figures 22 shows the simulated load-displacement histories of the neat PP and the syntactic PP foams at the dart impact test mode. As shown clearly, the simulated load-displacement history of neat PP was good agreement with the experimental result. In addition, the simulation result for the microballoon blended PP foam was also good agreement with the experimental results of the microballoon blended PPs (Balloon 80 and 120). In the SCF PP foams (SCF 50 and 250), the simulated load was relatively good agreement with the experimental result but the load softening needed to be improved. It is considered that the more detailed geometrical modeling would be needed for the non-uniform micro porous structures such as the elliptical-shape pores. This will be the future study. The present numerical result also indicates that the difference of the load-displacement history between the microballoon blended PP and the SCF PP foam would be caused by the different shape of the micro pores in PP matrix. Then, the microstructural aspects were investigated by conducting the microstructural FE analysis as described in the next section. 


\section{Craze}

density

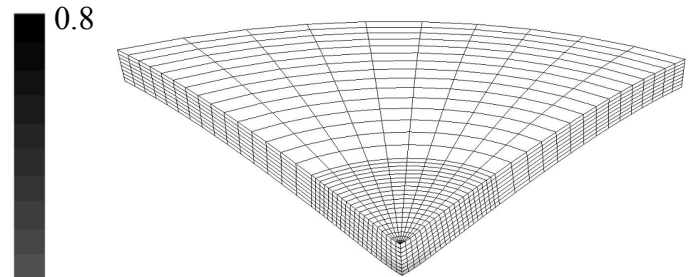

(i) Displacement $=5 \mathrm{~mm}$

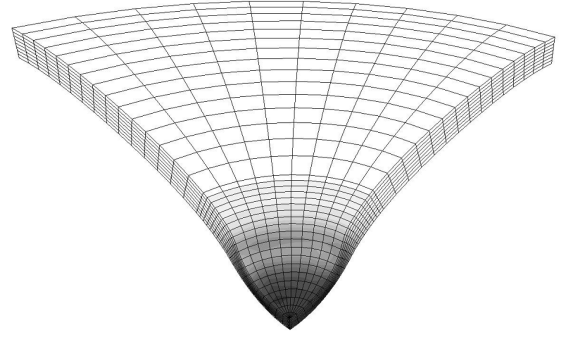

(iii) Displacement $=15 \mathrm{~mm}$

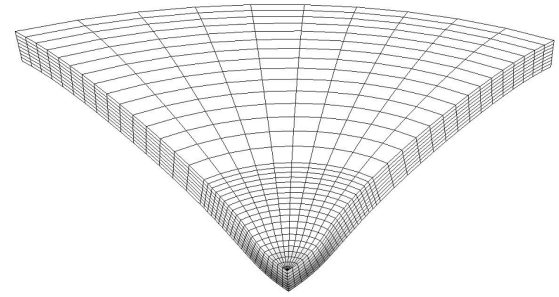

(ii) Displacement $=10 \mathrm{~mm}$

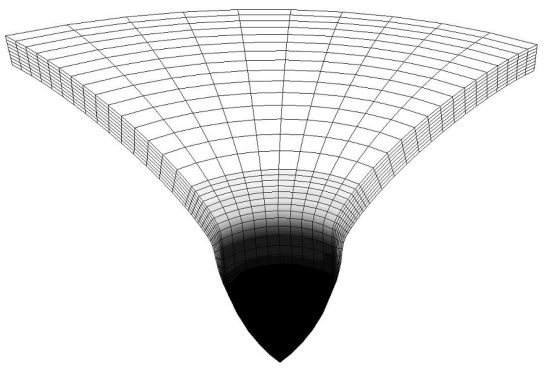

(iv) Displacement $=20 \mathrm{~mm}$

Figure 19 Snapshots of simulated deformation process of neat PP dart impact test specimen at the impact velocity of $10 \mathrm{~m} / \mathrm{s}$

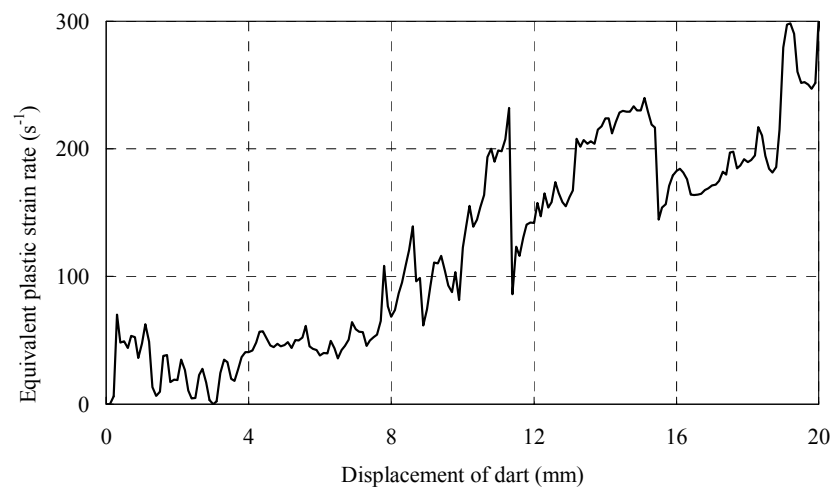

Figure 20 Equivalent plastic strain rate vs. dart displacement at the impact velocity of $10 \mathrm{~m} / \mathrm{s}$

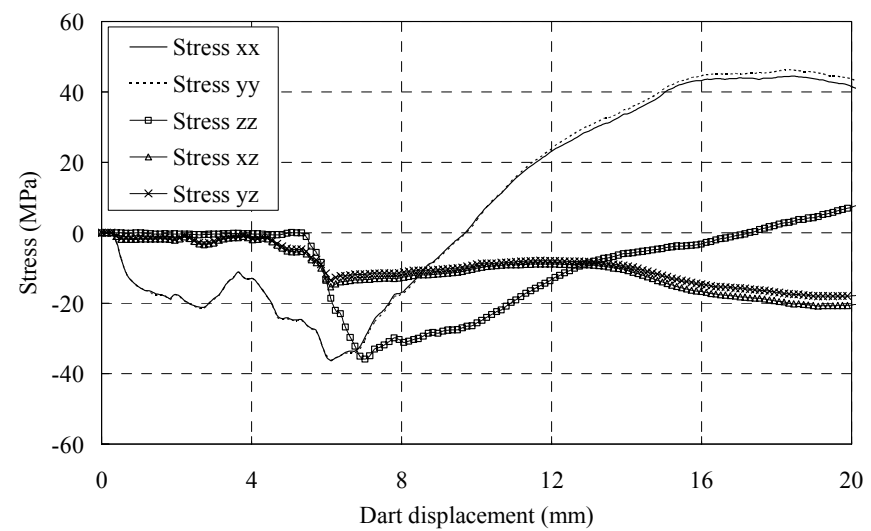

Figure 21 Stress states plotted against dart displacement at the impact velocity of $10 \mathrm{~m} / \mathrm{s}$ 


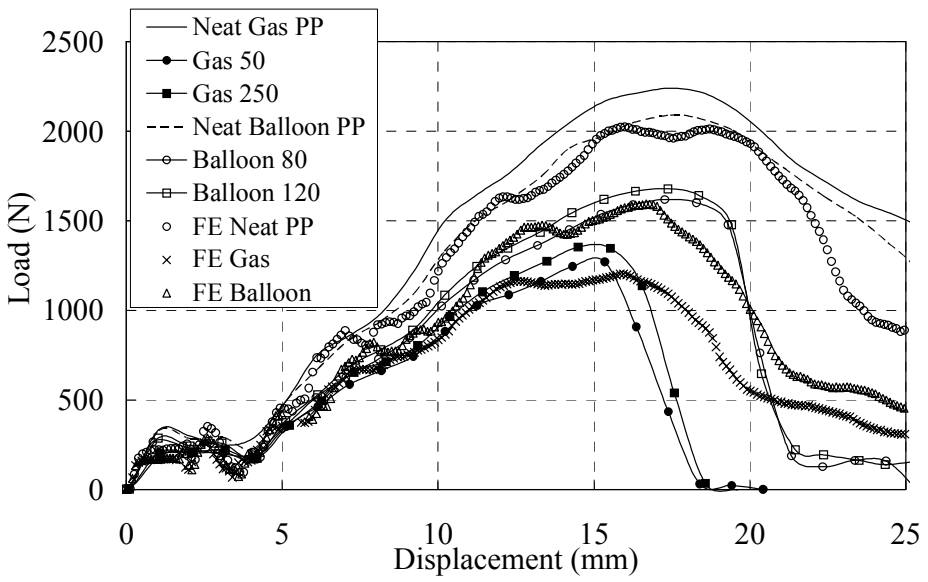

Figure 22 Simulated load displacement histories of neat PP and syntactic PP foam at the impact velocity of $10 \mathrm{~m} / \mathrm{s}$.

\subsection{Numerical Results: Microstructural Simulation}

Figure 23 shows the simulated equivalent stress distributions at the nominal strain rate of $10^{2} \mathrm{~s}^{-1}$, where the macroscopic nominal tensile strain was 0.03 . It is observed that the localized equivalent stress for the SCF gas foaming PP is larger, compared to that for the microballoon blended PP. In addition, the area of the high equivalent stress of the SCF gas foaming PP is larger than that for the microballoon blended PP. It is considered that this difference should delay the yielding of the microballoon blended PP, leading to the larger macroscopic yield stress than the SCF gas foaming PP in the tensile test. Figure 24 shows the equivalent stress distributions at the nominal strain rate of $10^{2} \mathrm{~s}^{-1}$, where the macroscopic nominal strain was 0.15 . As shown clearly in Fig. 24, the area of stress localization was larger in the case of the SCF gas foaming PP than the microballoon blended PP. Especially, the stress was localized at the ligaments between the long elliptical-shape micro pores in Gas 50 and 250. It is expected that the column like ligament would be broken in the case of the SCF gas foaming PP. On the contrary, the equivalent stress was uniform in the PP matrix, except for the narrow ligament between large balloons in the case of Balloon 120, leading to the smaller material ductility than that of Balloon 80 . This trend is similar to the experimental results as shown in Figs. 11 and 12.

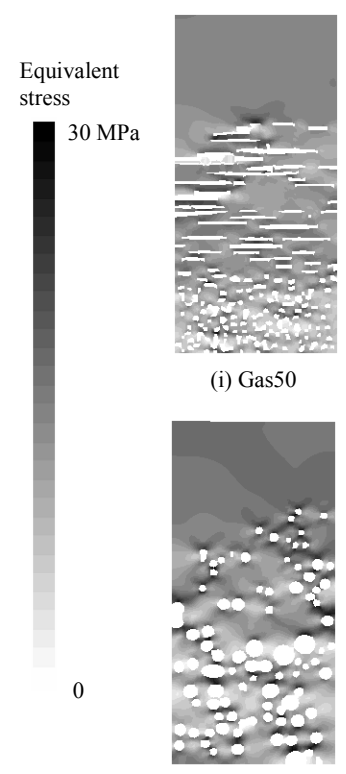

(iii) Balloon 80

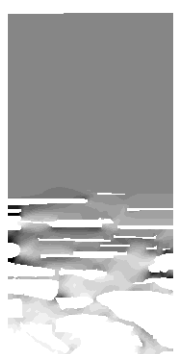

(ii) Gas 250

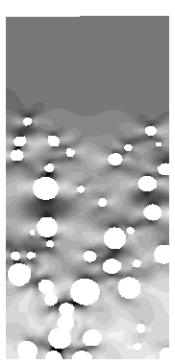

(iv) Balloon 120

Figure 23 Equivalent stress distribution at the nominal tensile strain of 0.03 


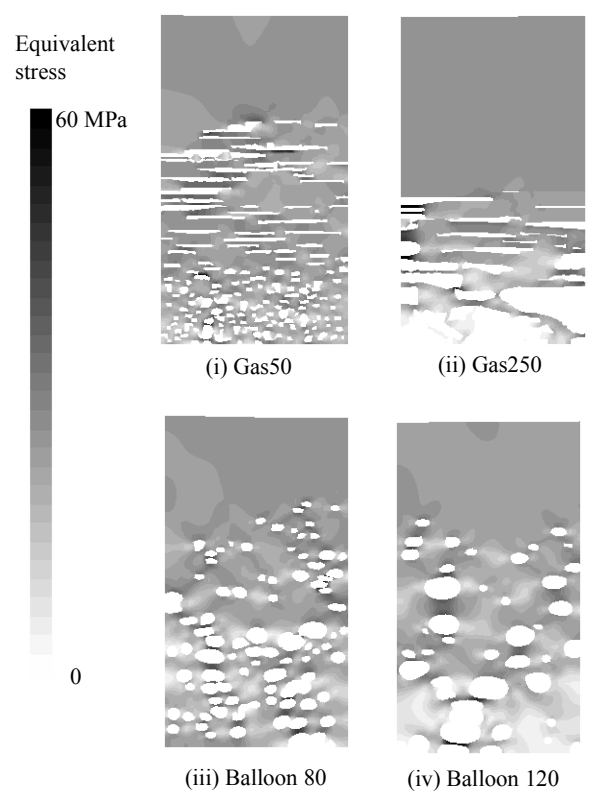

Figure 24 Equivalent stress distribution at the nominal tensile strain of 0.15

Figure 25 shows the equivalent stress distribution at the macroscopic nominal shear stress of 5.4 MPa when the simple shear deformation was applied at the nominal strain rate of $10^{2} \mathrm{~s}^{-1}$. As shown clearly, the stress was concentrated at both edges of the elliptical-shape micro pores in the cases of Gas 50 and 250. On the contrary, the area and the magnitude of the localized stresses were small in the microballoon blended PP, leading to the larger absorbed energy of the dart impact test mode in the case of the microballoon blended PP, compared to that of the SCF gas foaming PP. In addition, the magnitude of the localized stress was similar in the same type of PP foams (Gas 50 vs. Gas 250 and Balloon 80 vs. Balloon 250), leading to the similar absorbed energy within the same type of PP foams at the dart impact test. Thus, it is considered that the different local stress distribution caused by the shape of the micro pores leaded the different absorbed energy at the dart impact tests (Gas specimens vs. Balloon specimens).

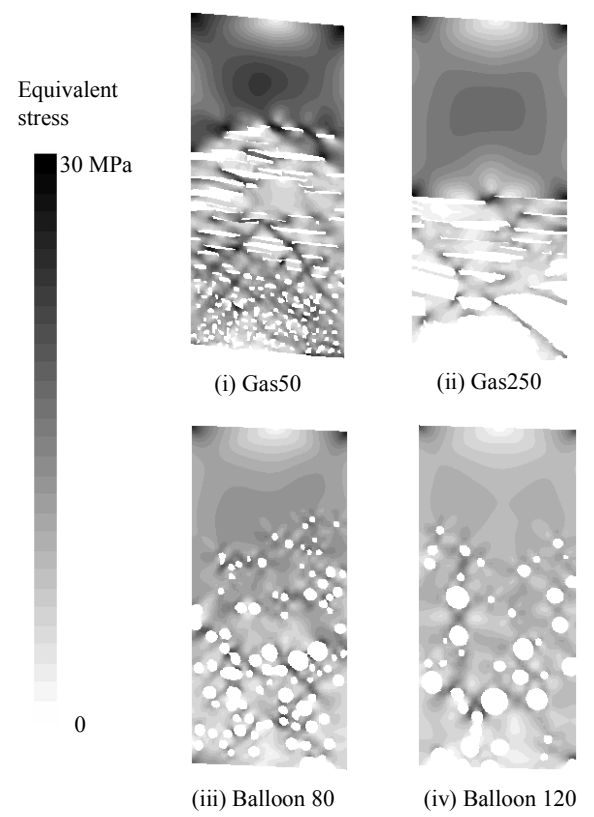

Figure 25 Equivalent stress distribution at the nominal shear stress of $5.4 \mathrm{MPa}$ 


\subsection{Effect of Micro Porous Shape on Mechanical Properties}

As a summary of obtained mechanical properties, the apparent elastic modulus and the strain energy up to failure were normalized by those of neat PPs. The elastic modulus and the strain energy up to failure were normalized by the mean elastic modulus and the strain energy of neat PPs. Figure 26 shows the relative elastic modulus plotted against the relative strain energy up to failure in the tensile tests. The relative apparent elastic modulus was the same between the microballoon blended PP and the SCF gas foaming PP. On the contrary, the relative strain energy up to failure of the microballoon blended PP was a little larger than that of the SCF gas foaming PP. However, the variation of the relative strain energy up to failure was broad in the microballoon blended PP. Thus, it is considered that the difference of the shape of the micro pores should not have a significant effect on the macroscopic mechanical properties under the tensile loading condition. Figure 27 shows the relative maximum load plotted against the relative absorbed energy up to failure in the dart impact test. The relative maximum load of the microballoon blended PP was a little larger than that of the SCF gas foaming PP. On the contrary, the significant difference was obtained in the relative absorbed energy up to failure of the dart impact tests. The relative absorbed energy up to failure of the microballoon blended PP was about 1.4 times as large as that of the SCF gas foaming PP. This is because the stress is localized at the edges of the elliptical-shape micro porous structure in the SCF gas foaming PP, especially under the shear deformation. However, the edges of the elliptical-shape micro pores were not the stress concentration cite under tensile loading, according to the microstructural FE analysis. Thus, it is considered that the shape of the micro pores in the PP matrix should have strong effect on the dart impact loading case only.

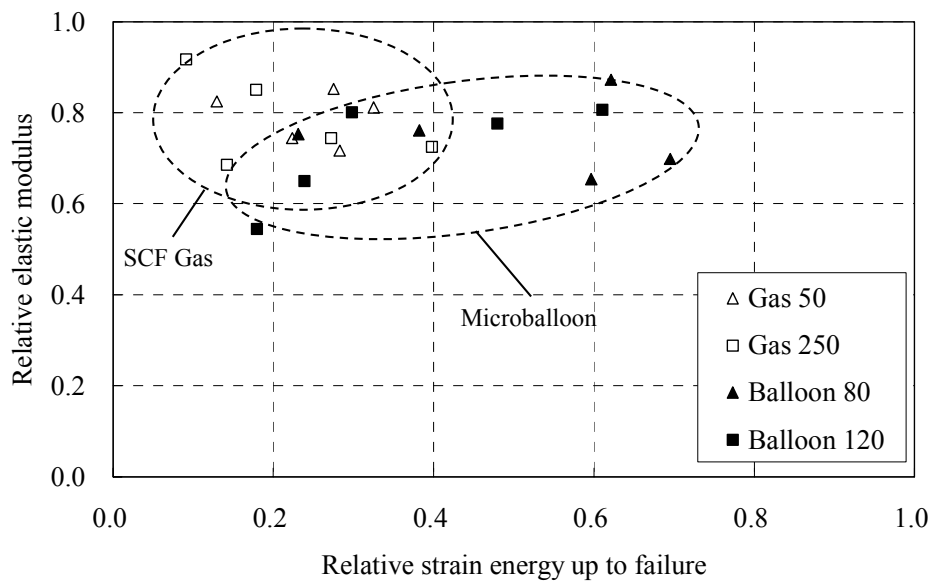

Figure 26 Relative elastic modulus vs. relative strain energy up to failure

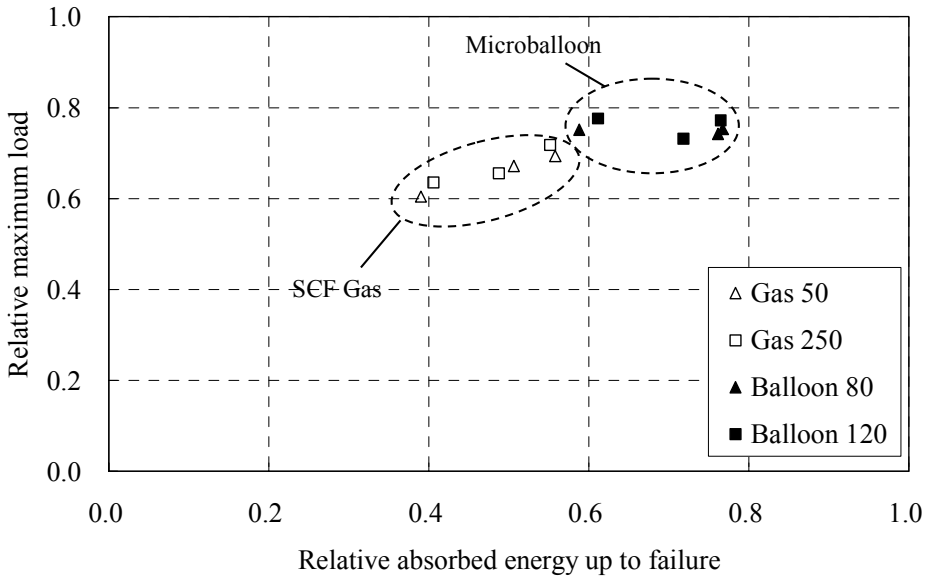

Figure 27 Relative maximum load vs. relative absorbed energy up to failure 


\section{Conclusion}

The effect of the microstructure of the pores inside the matrix on the mechanical properties of the thermoplastic syntactic PP foams at the intermediate and high strain rates was characterized. In addition, the constitutive law with craze evolution was modified by introducing the relative density, the stress concentration coefficient and the volume fraction of cell edge of the pore for predicting the mechanical behavior of the syntactic PP foams. The followings are the conclusion of this study:

1. In the tensile loading, the apparent elastic modulus was not influenced by the shape of the micro pores in the PP matrix while the macroscopic yield stress and the strain energy up to failure were relatively influenced by the shape of micro pores. The microstructural finite element analyses showed that the magnitude of the localized stresses at the edges and the ligaments of the elliptical-shape micro pores was larger than that of the spherical micro pores, leading to the early yielding and less material ductility.

2. In the case of the dart impact loading, the microstrure of pores had strong effect on the absorbed energy. This is because the elliptical-shape micro pores were very sensitive to the shear deformation, which was revealed by the microstructural finite element analyses.

3. The constitutive law with craze evolution was modified by introducing the relative density, the stress concentration coefficient and the volume fraction of cell edge. The modified constitutive law successfully predicted the load-displacement relationship of the dart impact loading in the microballoon blended PP foam while that of the SCF gas foaming PP was to be further explored for improving the modeling. It was investigated that the present constitutive law could predict the load-displacement histories of the spherical-shape micro porous PP foams at the dart impact loading.

4. It was concluded that the micro porous shape had strong effect on the material ductility especially under dart impact loading, leading to the possibility to control the material ductility by the shape of the micro pores in the polymeric foams.

The polymer based syntactic foam has an advantage in light weight, low cost and good productivity for the applications not only in automobile but also in any other field, such as airplane, mobile computers, packaging and so on. Therefore, more detailed studied are encouraged. Especially, the relations between the three-dimensional shape of the micro pores and global mechanical behaviors in such heterogeneous microstructures are left as future works.

\section{References}

(1) Mae H., Teng X., Bai Y., Wiezbicki T., Mater. Sci. Eng. A, Vol. 459 (2007), pp. 156-166.

(2) Mae H., Teng X., Bai Y., Wiezbicki T., Int. J. Solids Struct., Vol. 45 (2008), pp. 1430-1444.

(3) Mae H., Teng X., Bai Y., Wiezbicki T., J. Japanese Soc. Exp. Mech., Vol. 8 (2008), pp. 45-51.

(4) Mae H., Omiya M., Kishimoto K., Trans. Japan Soc. Computational Methods Eng., Vol. 7 (2008), pp. 203-206.

(5) Van der Waal A., Nijhof R., Gaymans R.J., Polymer, Vol. 40 (1999), pp.6031-6044.

(6) Liu Y.Q., Kontopoulou M., Polymer, Vol. 47 (2006), pp. 7731-7739.

(7) Premphet K., Horanont P., J. Appl. Polym., Sci., Vol. 76 (2000), pp. 1929-1939.

(8) Mae H., Omiya M., Kishimoto K., J. Appl. Polym. Sci., Vol. 107 (2008), pp. 3520-3528.

(9) Mae H., Omiya M., Kishimoto K., J. Soc. Mater. Sci. Japan, (2008), in press.

(10) Rong M.Z., Zhang M.Q., Zheng Y.X., Zeng H.M., Walter R., Friedrich K., J. Mater. Sci. Lett., Vol. 19 (2000), pp. 1159-1161.

(11) Fekete W., Molnar Sz., Kim G.-M., Michler G.H., Pukanszky B., J. Macromol. Sci. B, Vol. 38 (1999), pp.885-899. 
(12) Chan C.-M., Wu J., Li J.-X., Cheung, Y.-K., Polymer, Vol. 43 (2002), pp. 2981-2992.

(13) Mae H., Omiya M., Kishimoto K., J. Solid Mech. Mater. Eng., Vol. 2 (2008), pp. 254-268.

(14) Mae H., Omiya M., Kishimoto K., Trans. Japan Soc. Computational Methods Eng., Vol. 7 (2008), pp. 207-212.

(15) Shutov F.A., Adv. Polym. Sci., Vol.73/74 (1986), pp. 63-123.

(16) Lawrence E., Pyrz R., Polym. Comp., Vol. 9 (2001), pp. 227-238.

(17) Whinnery L., Goods S., Even B., Sandia Report, Vol.30 (2000), pp. 8217.

(18) Saha M.C., Mahfuz H., Chakravarty U.K., Uddin M., Kabir Md.E., Jeelani S., Mater. Sci. Eng. A., Vol. 406 (2005), pp.328-336.

(19) Subhash G., Liu Q., Gao, X.-L., Int. J. Impact. Eng., Vol. 32 (2006), pp.1113-1126.

(20) Ouellet S., Cronin D., Worswick M., Polym. Test., Vol. 25 (2006), pp.731-743.

(21) Mae H., Omiya M., Kishimoto K., Mater. Sci. Eng. A, Vol. 477 (2008), pp. 168-178.

(22) Mae H., Kishimoto K., Trans. Soc. Automotive Engineers Japan, Vol. 38 (2007), pp.63-68.

(23) Murakami D., Kobayashi S., Torigaki T., Shizawa K., Trans. Japan Soc. Mechanical Engineers A, Vol. 68 (2002), pp. 674-681.

(24) Murakami D., Kobayashi S.,Torigaki T., Shizawa, K., Trans. Japan Soc. Mechanical Engineers A, Vol. 68 (2002), pp. 682-689.

(25) Kobayashi S.,Tomii D., Shizawa K., Trans. Japan Soc. Mechanical Engineers A, Vol. 70 (2004), pp. 810-817.

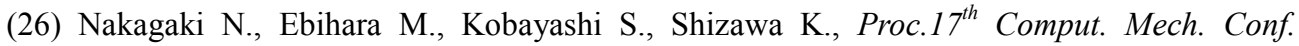
(2004), pp. 129-130.

(27) Mae H., Kishimoto K., J. Solid Mech. Mater. Eng., Vol. 1, No.1 (2007), pp.35-45.

(28) Martini J.E., Waldman F.A., Suh N.P., Soc. Plast. Eng. Tech. Papers, Vol. 28 (1982), pp.674-676.

(29) Colton J.S., Suh N.P., Adv. Manuf. Proc., Vol. 1 (1986), pp.341-364.

(30) Park C.B., Cheung L.K., Polym. Eng. Sci., Vol. 37 (1997), pp.1-10.

(31) Gibson L.J., Ashby M.F., Cellular Solids, $2^{\text {nd }}$ edition (1997).

(32) Li H.R., Polym. Testing, Vol. 16 (1997), pp. 429-443.

(33) Goods S.H., Neuschwanger C.L., Whinnery L.L., Mater. Res. Soc. Sym. Proc. Vol. 521 (1998), pp. 15-22.

(34) Sun H., Sur G.S., Mark J.E., Euro. Polym. J., Vol. 38 (2002), pp. 2373-2381.

(35) http://www.ctcms.nist.gov/oof/ 